\title{
Aspirin for primary prevention of stroke in traumatic cerebrovascular injury: association with increased risk of transfusion
}

\author{
Russell L. Griffin, PhD, ${ }^{1}$ Stephanie R. Falatko, DO, ${ }^{2}$ Stella Aslibekyan, PhD, ${ }^{1}$ \\ Virginia Strickland, MD, ${ }^{3}$ and Mark R. Harrigan, MD² \\ 'Department of Epidemiology; ' ${ }^{2}$ Department of Neurosurgery; and ${ }^{3}$ Section of Trauma and Acute Care Surgery, Department of
Surgery, University of Alabama, Birmingham, Alabama
}

\begin{abstract}
OBJECTIVE Blunt traumatic extracranial carotid or vertebral artery injury (i.e., traumatic cerebrovascular injury [TCVI]) occurs in $1 \%-2 \%$ of all blunt trauma admissions, carries a $10 \%$ risk of thromboembolic ischemic stroke, and accounts for up to 9600 strokes annually in the US. Screening CT angiograms (CTAs) of patients with trauma has become ubiquitous in recent years, and patients with initially asymptomatic TCVI are commonly treated with antiplatelet agents to prevent stroke. Prophylaxis with antiplatelets is thought to be safer than anticoagulation, which carries a significant risk of hemorrhage in patients with trauma. However, the risk of hemorrhagic complications due to antiplatelets has not been assessed in this population.
\end{abstract}

METHODS This is a retrospective cohort study of patients in whom a screening CTA was obtained after admission for blunt trauma at a Level 1 trauma center. Patients with CTAs indicating TCVI were treated routinely with $325 \mathrm{mg}$ aspirin daily. The risk of transfusion > 24 hours after admission was compared according to CTA findings (CTA+ or CTA- for positive or negative findings, respectively) and aspirin treatment (ASA+ or ASA- for treatment or no treatment, respectively).

RESULTS The mean overall transfusion amount (number of units of packed red blood cells [PRBCs]) was $0.9 \pm 2.1$ for CTA+/ASA+ patients $(n=196)$ and $0.3 \pm 1.60$ for CTA-/ASA- patients $(n=2290)(p<0.0001)$. In adjusted models, the overall relative risk (RR) of PRBC transfusion was 1.70 (1.32-2.20) for CTA+/ASA+ patients compared with CTA-/ASApatients. Among age groups, participants whose ages were 50-69 years had the greatest significantly elevated RR (1.71, 95\% Cl 1.08-2.72) for CTA+/ASA+ patients compared with CTA-/ASA- patients.

CONCLUSIONS Treatment with aspirin for the prevention of stroke in patients with initially asymptomatic TCVI carries a significantly increased risk of PRBC transfusion. Future studies are needed to determine if this risk is offset by a reduced risk of ischemic stroke.

https://thejns.org/doi/abs/10.3171/2017.12.JNS172284

KEYWORDS stroke; blunt trauma; dissection; antiplatelets; hemorrhage; primary prevention; vascular disorders

E XTRACRANIAL traumatic cerebrovascular injury (TCVI) is present in $1 \%-2 \%$ of patients admitted after high-energy blunt trauma, such as motor vehicle crashes and falls. ${ }^{15,18,37}$ Research has reported that $10 \%-20 \%$ of patients with TCVI have an ischemic stroke, $,, 16,37$ and that TCVI may be the primary cause of up to 9600 ischemic strokes in the US per year. ${ }^{14}$ TCVI is also associated with the majority of ischemic stroke cases among patients with traumatic brain injury. ${ }^{22}$

Patients admitted with blunt trauma and risk factors for TCVI routinely undergo a screening neck CT angiogram (CTA) to look for TCVI. Due to the increasing use of screening CTAs for this purpose, the estimates of TCVI incidence have been growing at a significant rate over the

ABBREVIATIONS ASA+, ASA - = with aspirin treatment, without aspirin treatment; CTA = CT angiogram; CTA+, CTA- = CTA positive for TCVI, CTA negative for TCVI; GCS = Glasgow Coma Scale; INR = international normalized ratio; ISS = Injury Severity Score; LOS = length of stay; PRBC = packed red blood cell; RERI = relative excess risk due to interaction; $\mathrm{RR}$ = relative risk; $\mathrm{TCVI}$ = traumatic cerebrovascular injury.

SUBMITTED September 13, 2017. ACCEPTED December 19, 2017.

INCLUDE WHEN CITING Published online May 18, 2018; DOI: 10.3171/2017.12.JNS172284. 
last decade. ${ }^{18}$ The majority of TCVIs identified by screening CTAs are initially asymptomatic. ${ }^{16,37}$ Because most ischemic strokes are thromboembolic, ${ }^{16}$ prophylactic treatment with antithrombotic medications is preferred by the majority of clinicians who manage patients with TCVI. ${ }^{19}$ Although systemic anticoagulation is contraindicated in one-third of trauma patients due to other injuries, ${ }^{37,41}$ evidence suggests that antiplatelet agents carry a lower risk of hemorrhagic complications and are therefore used as an alternative to anticoagulation in many centers., ${ }^{9,14,41}$ However, the risk of hemorrhagic complications due to antiplatelet agents has not been assessed in the TCVI population. We sought to determine if treatment of TCVI patients with antiplatelet agents is associated with a higher risk of hemorrhagic complications, as reflected by the risk of blood transfusion.

\section{Methods \\ Study Design}

This was an institutional review board-approved retrospective cohort study at an American College of Surgeons Level 1-verified trauma center. Standard management of patients with blunt trauma at our center includes a screening neck CTA on admission to assess for TCVI; most patients with a CTA interpreted as showing evidence of injury (CTA+) to the extracranial carotid or vertebral arteries are treated with aspirin (ASA+) $-325 \mathrm{mg}$ orally or per rectum daily for the duration of the hospital stay. Anticoagulation for the treatment of TCVI is generally avoided.

\section{Data Sources}

An administrative database was used to generate a list of all patients admitted to our center with a diagnosis of blunt trauma and undergoing a neck CTA on admission between January 1, 2013, and December 31, 2016. Demographic data (i.e., age, race, and sex) and injury characteristics (i.e., mechanism, Injury Severity Score [ISS], and Glasgow Coma Scale [GCS] score at hospital presentation) were obtained from the hospital's trauma registry. Clinical characteristic and outcome data were collected from a query of the hospital's electronic medical record data table. Clinical characteristics included base excess, lactic acid, systolic blood pressure, and international normalized ratio (INR) on hospital admission. Clinical outcomes included data related to transfusion of packed red blood cells (PRBCs), mean hospital length of stay (LOS), ICU LOS, ventilator support days, and nosocomial occurrence of pneumonia, adult respiratory distress syndrome, and acute kidney injury. Additional data on CTA+ patients were obtained from a prospective center database on patients with TCVI.

\section{Variable Definitions}

Race was defined as white, black, and other (the latter was combined into a single category due to small sample sizes of patients in non-white and non-black racial categories). Age was categorized as 18-29 years, 30-49 years, $50-69$ years, and $\geq 70$ years. The INR was dichotomized as evidence of coagulopathy (i.e., INR $\geq 1.2$ ) and no evi- dence of coagulopathy (i.e., INR < 1.2). The injury mechanism was defined as blunt or penetrating. The ISS was categorized as minor injury (i.e., 1-14), moderate injury (15-24), and severe injury ( $\geq 25)$. The GCS score was categorized as traumatic brain injury (i.e., GCS score 3-8), mild/moderate head injury (i.e., GCS score 9-12), and no head injury (i.e., GCS score 13-15). Systolic blood pressure was categorized as $<90 \mathrm{~mm} \mathrm{Hg}$ and $\geq 90 \mathrm{~mm} \mathrm{Hg}$. Using methodology proposed by Quan and colleagues, ${ }^{31}$ the ICD diagnosis codes from billing data were used to identify comorbidities, including myocardial infarction, congestive heart failure, peripheral vascular disease, cerebrovascular disease, rheumatic disease, peptic ulcer disease, chronic obstructive pulmonary disease, dementia, liver disease, diabetes, hemi- or paraplegia, renal disease, malignancy, metastasis, and HIV/AIDS.

The main exposures were positive CTA and use of ASA (i.e., CTA+ and ASA+). Patients were classified according to whether the neck CTA showed evidence of a TCVI (CTA+) or no evidence of TCVI (CTA-), and whether each patient was treated with aspirin (i.e., ASA+) or was not treated with aspirin (ASA-). The outcome of interest was the need for transfusion following the initial 24-hour resuscitative period. Only transfusions $>24$ hours after admission were included as the main outcome, to exclude initial transfusions given for injury-related blood loss.

\section{Statistical Analysis}

Demographic, injury, comorbidity, and clinical characteristics and outcomes were compared among the CTA/ ASA groups by using an ANOVA or Pearson's chi-square test for continuous and categorical variables, respectively. A Cox proportional hazards regression assuming equal time at risk was used to estimate relative risks (RRs) and associated 95\% confidence intervals for the association between CTA/ASA exposure and need for transfusion of PRBCs after 24 hours. Models were adjusted for the following: age; ISS; diagnosis of myocardial infarction, congestive heart failure, or peripheral vascular disease; number of PRBC units transfused in the first 24 hours of admission; and having an INR $\geq 1.2$ at admission. A relative excess risk due to interaction (RERI) was used to examine whether the combined exposure of $\mathrm{CTA}+1$ ASA+ resulted in an absolute increased risk of PRBC transfusion outside of the expected risk due to CTA+ and ASA+ separately (i.e., additive interaction). A positive RERI suggests a higher risk than expected, a negative RERI suggests a lower risk, and a RERI of 0 suggests no different risk than expected. Due to the fact that the patient population probably included individuals who were already taking aspirin or other antiplatelet agents at the time of admission, a characteristic for which we were not able to collect data due to the retrospective nature of the study design, models were stratified by age category in an effort to account for the likelihood of preinjury use of antiplatelet agents.

\section{Results}

A total of 2867 patients were included, of whom 196 
TABLE 1. Comparison of demographic, injury, clinical presentation, and clinical outcome characteristics by CTA and ASA status

\begin{tabular}{|c|c|c|c|c|c|}
\hline Characteristic & $C T A+/ A S A+, n=196$ & $C T A+/ A S A-, n=86$ & CTA-IASA+, n = 295 & CTA-IASA-, $n=2290$ & $p$ Value* \\
\hline \multicolumn{6}{|l|}{ Demographics } \\
\hline \multicolumn{6}{|l|}{$\operatorname{Sex}(\%)$} \\
\hline Male & $119(60.7)$ & $50(58.1)$ & $194(65.8)$ & $1545(67.5)$ & 0.0829 \\
\hline Female & $77(39.3)$ & $36(41.9)$ & $101(34.2)$ & $745(32.5)$ & \\
\hline \multicolumn{6}{|l|}{ Race (\%) } \\
\hline Black & $43(22.1)$ & $23(26.7)$ & $57(19.3)$ & $578(25.5)$ & 0.1471 \\
\hline White & $144(73.8)$ & $60(69.8)$ & $216(73.2)$ & $1548(68.3)$ & \\
\hline Other & $8(4.1)$ & $3(3.5)$ & $22(7.5)$ & $142(6.3)$ & \\
\hline Mean age in yrs & $45.0 \pm 19.0$ & $46.0 \pm 19.8$ & $51.7 \pm 19.9$ & $40.5 \pm 17.8$ & $<0.0001$ \\
\hline $18-29$ & $56(28.6)$ & $24(27.9)$ & $49(16.6)$ & $791(34.5)$ & $<0.0001$ \\
\hline $30-49$ & $61(31.1)$ & $23(26.7)$ & $80(27.1)$ & $819(35.8)$ & \\
\hline $50-69$ & $57(29.1)$ & $27(31.3)$ & $195(35.6)$ & $522(22.8)$ & \\
\hline$\geq 70$ & $22(11.2)$ & $12(14.0)$ & $61(20.7)$ & $158(6.9)$ & \\
\hline \multicolumn{6}{|l|}{ Injury } \\
\hline Blunt mechanism (\%) & $192(98.0)$ & $82(95.3)$ & $291(98.6)$ & $2211(96.6)$ & 0.1598 \\
\hline Mean ISS & $21.2 \pm 11.4$ & $21.4 \pm 15.7$ & $18.7 \pm 12.4$ & $11.9 \pm 10.4$ & $<0.0001$ \\
\hline $1-14$ & $64(32.7)$ & $32(37.6)$ & $136(46.1)$ & $1624(71.0)$ & $<0.0001$ \\
\hline $15-24$ & $67(34.2)$ & $23(27.1)$ & $95(32.2)$ & $402(17.6)$ & \\
\hline$\geq 25$ & $65(33.2)$ & $30(35.3)$ & $64(21.7)$ & $262(11.5)$ & \\
\hline Mean GCS score & $12.2 \pm 4.6$ & $10.2 \pm 5.5$ & $12.8 \pm 4.2$ & $13.5 \pm 3.6$ & $<0.0001$ \\
\hline $3-8$ & $40(20.6)$ & $34(40.0)$ & $50(17.1)$ & $257(11.3)$ & $<0.0001$ \\
\hline $9-12$ & $12(6.2)$ & $3(3.5)$ & $8(2.7)$ & $58(2.5)$ & \\
\hline $13-15$ & $142(73.2)$ & $48(56.5)$ & $234(80.1)$ & $1966(86.2)$ & \\
\hline \multicolumn{6}{|l|}{ Clinical presentation } \\
\hline Mean base excess & $-3.0 \pm 3.6$ & $-4.6 \pm 5.5$ & $-3.2 \pm 4.0$ & $-2.2 \pm 3.5$ & $<0.0001$ \\
\hline Mean lactic acid & $2.4 \pm 1.9$ & $3.2 \pm 2.8$ & $2.5 \pm 1.9$ & $2.3 \pm 2.1$ & 0.0009 \\
\hline Mean systolic blood pressure & $133.3 \pm 27.0$ & $132.2 \pm 39.9$ & $133.6 \pm 27.2$ & $137.0 \pm 25.6$ & 0.0367 \\
\hline$<90$ mm Hg (\%) & $6(3.1)$ & $8(11.8)$ & $16(5.5)$ & $35(1.9)$ & $<0.0001$ \\
\hline Mean INR & $1.11 \pm 0.23$ & $1.16 \pm 0.51$ & $1.13 \pm 0.38$ & $1.09 \pm 0.76$ & 0.5339 \\
\hline$\geq 1.2(\%)$ & $32(16.4)$ & $19(22.9)$ & $56(19.1)$ & $243(10.8)$ & $<0.0001$ \\
\hline \multicolumn{6}{|l|}{ Clinical outcome } \\
\hline \multicolumn{6}{|l|}{ Mean units PRBCs } \\
\hline First 24 hrs & $0.9 \pm 2.1$ & $1.2 \pm 3.0$ & $1.0 \pm 2.4$ & $0.3 \pm 1.6$ & $<0.0001$ \\
\hline Overall & $2.9 \pm 4.9$ & $1.8 \pm 3.6$ & $2.7 \pm 4.6$ & $0.8 \pm 2.8$ & $<0.0001$ \\
\hline Mean hospital LOS, days & $15.2 \pm 18.0$ & $7.6 \pm 13.0$ & $13.8 \pm 13.1$ & $5.4 \pm 9.0$ & $<0.0001$ \\
\hline Mean ICU LOS, days & $14.9 \pm 15.7$ & $11.8 \pm 17.0$ & $12.7 \pm 10.8$ & $9.2 \pm 9.3$ & $<0.0001$ \\
\hline Mean ventilator support, days & $13.8 \pm 14.2$ & $9.4 \pm 14.3$ & $11.3 \pm 9.7$ & $7.4 \pm 7.9$ & $<0.0001$ \\
\hline Pneumonia (\%) & $21(10.7)$ & $8(9.3)$ & $20(6.8)$ & $60(2.6)$ & $<0.0001$ \\
\hline Adult respiratory distress syndrome (\%) & $4(2.0)$ & $1(1.2)$ & $2(0.7)$ & $5(0.2)$ & 0.0010 \\
\hline Acute kidney injury (\%) & $4(2.0)$ & $1(1.2)$ & $9(3.1)$ & $12(0.5)$ & $<0.0001$ \\
\hline
\end{tabular}

The mean values are expressed \pm SD; otherwise the values represent number of patients (\%).

* Estimated from chi-square and ANOVA for categorical and continuous variables, respectively.

(6.8\%) were CTA+/ASA+, 86 (3.0\%) were CTA+/ASA-, $295(10.3 \%)$ were CTA-/ASAt, and 2290 (79.9\%) were CTA-/ASA-. There was no difference in sex or race among the exposure groups; however, the CTA-/ASAgroup was younger than the other exposure groups $(\mathrm{p}<$ 0.0001 ) (Table 1). In addition, the CTA-/ASA- group had the lowest ISS $(\mathrm{p}<0.0001)$ and higher GCS $(\mathrm{p}<0.0001)$ than the other exposure groups. Examining clinical presentation characteristics, base excess was lowest for the CTA-/ASA- group $(\mathrm{p}<0.0001)$, whereas the CTA+/ ASA- group had higher lactic acid levels $(p=0.0009)$ and was more likely to have a systolic blood pressure $<90$ $\mathrm{mm} \mathrm{Hg}(\mathrm{p}<0.0001)$ and to be coagulopathic ( $<0.0001)$. Those who were CTA-/ASA- had a lower likelihood of 
TABLE 2. Comparison of comorbidities by CTA and ASA status

\begin{tabular}{|c|c|c|c|c|c|}
\hline Comorbidities & CTA $+/ A S A+, n=196$ & CTA $+/ A S A-, n=86$ & CTA-IASA,$+ n=295$ & CTA-/ASA-, $n=2290$ & $p$ Value ${ }^{*}$ \\
\hline Myocardial infarction & 6.1 & 1.3 & 13.2 & 1.8 & $<0.0001$ \\
\hline Congestive heart failure & 2.6 & 3.8 & 12.2 & 1.3 & $<0.0001$ \\
\hline Peripheral vascular disease & 7.1 & 6.4 & 12.5 & 4.1 & $<0.0001$ \\
\hline Cerebrovascular disease & 24.5 & 23.4 & 23.7 & 8.0 & $<0.0001$ \\
\hline Rheumatic disease & 0.5 & 0.0 & 2.0 & 0.8 & 0.1421 \\
\hline Peptic ulcer disease & 0.5 & 1.3 & 0.7 & 0.1 & 0.0858 \\
\hline Chronic obstructive pulmonary disease & 8.7 & 5.1 & 15.9 & 8.4 & 0.0002 \\
\hline Dementia & 2.6 & 1.3 & 2.7 & 1.1 & 0.0557 \\
\hline Mild liver disease & 2.0 & 6.4 & 4.7 & 5.6 & 0.1846 \\
\hline \multicolumn{6}{|l|}{ Diabetes } \\
\hline w/o chronic complications & 16.8 & 12.8 & 26.8 & 9.3 & $<0.0001$ \\
\hline w/ chronic complications & 0.5 & 0.0 & 1.7 & 0.1 & $<0.0001$ \\
\hline Hemiplegia or paraplegia & 7.1 & 7.7 & 5.1 & 1.9 & $<0.0001$ \\
\hline Renal disease & 4.6 & 3.8 & 4.1 & 1.3 & 0.0001 \\
\hline Malignancy & 0.0 & 0.0 & 1.7 & 0.9 & 0.1906 \\
\hline Moderate or severe liver disease & 0.0 & 0.0 & 0.0 & 0.3 & 0.6505 \\
\hline Metastasis & 0.0 & 0.0 & 0.0 & 0.4 & 0.4822 \\
\hline HIVIAIDS & 0.0 & 0.0 & 0.0 & 0.1 & 0.8450 \\
\hline
\end{tabular}

The list of comorbidities is from Quan H, Sundararajan V, Halfon P, et al: Coding algorithms for defining comorbidities in ICD-9-CM and ICD-10 administrative data. Med Care 43:1130-1139, 2005. Values are expressed as percentages.

* Estimated from chi-square test.

transfusion, both within the first 24 hours $(\mathrm{p}<0.0001)$ and after 24 hours $(p<0.0001)$. Regarding clinical outcomes, the CTA+/ASA+ group had longer ICU stays $(p<0.0001)$, ventilator support days $(\mathrm{p}<0.0001)$, and overall hospital LOS $(p<0.0001)$. None of the patients in the CTA+/ASA+ group had any hemorrhagic complications that were directly attributable to treatment with aspirin.

The likelihood of having an ICD diagnosis code, whether present on admission or not, for myocardial infarction ( $p<0.0001)$, congestive heart failure $(p<0.0001)$, peripheral vascular disease $(p<0.0001)$, diabetes $(p<0.0001)$, and chronic obstructive pulmonary disease $(\mathrm{p}=0.0002)$ was highest for those who were CTA-/ASA+ (Table 2). Hemiplegia/paraplegia was highest for CTA+ patients ( $\mathrm{p}<$ 0.0001 ), and renal disease was lowest for those who were CTA-/ASA- $(\mathrm{p}=0.0001)$.

In overall crude models with the CTA-/ASA- groups as the referent, use of aspirin was associated with increased risk of transfusion, with significantly increased RRs for both the CTA+/ASA+ (RR 2.75, 95\% CI 2.14-3.53) and CTA-/ASA+ (RR 3.36, 95\% CI 2.75-4.10) exposure groups (Table 3 ). In adjusted models the associations remained, although they were attenuated in strength for both the CTA+/ASA+ (RR 1.70, 95\% CI 1.32-2.20) and CTA-/ ASA+ (RR 2.02, 95\% CI 1.64-2.51) groups. The RERI for the trauma population overall was -0.20 with a $95 \%$ $\mathrm{CI}$ of -0.88 to 0.47 , suggesting that the risk of transfusion after 24 hours for the combined CTA+/ASA+ group was no different than expected. In other words, the increased RR for the CTA+/ASA+ was due to the individual effects of cerebrovascular injury and the aspirin, not because of the combination of the two. By age groups, a similar pat- tern of associations was observed for all age groups. That is, we observed increased RRs for the CTA+/ASA+ and CTA-/ASA+ and a nonsignificant RERI.

\section{Discussion}

Our study found that use of aspirin in patients who suffered blunt trauma with or without evidence of TCVI on the screening neck CTA upon admission is associated with a significantly higher risk of transfusion compared to patients with blunt trauma who had CTA- and ASA- status. However, specific to CTA+ patients, the use of aspirin confers no more risk than was expected from TCVI alone (i.e., without accounting for use of aspirin) and use of aspirin alone (i.e., without accounting for presence of TCVI). This pattern of results was consistent across all age groups.

Our finding of no hemorrhagic complications directly attributable to aspirin is consistent with other studies of aspirin in the treatment of TCVI. ${ }^{16,38}$ Considering that no obvious hemorrhagic events due to aspirin occurred in CTA+ patients, it is likely that the greater transfusion risk in these patients was the result of more subtle effects on blood loss during trauma-related orthopedic and other surgical procedures, and other causes of bleeding due to the trauma $>24$ hours after injury.

Traumatic cerebrovascular injury is significantly different from spontaneous carotid and vertebral artery dissection, and from dissections occurring after low-energy trauma. Spontaneous arterial dissections, and dissections that occur after coughing fits, rapid head turning, or rapid neck extension, have been studied extensively. The risk of stroke with spontaneous and low-energy dissections was 
TABLE 3. RRs and associated $95 \% \mathrm{Cls}$ for the association between interactions of CTA and ASA status and need for transfusion after 24 hours, with additional measures of RERI

\begin{tabular}{|c|c|c|c|c|}
\hline Patient Groups & No. Needing Transfusion After 24 Hrs (\%) & Crude RR $(95 \% \mathrm{Cl})^{*}$ & Adjusted RR $(95 \% \mathrm{Cl}) \dagger$ & RERI (95\% Cl) \\
\hline \multicolumn{5}{|l|}{ Overall } \\
\hline CTA+/ASA+ & $75(38.3)$ & $2.75(2.14-3.53)$ & $1.70(1.32-2.20)$ & $-0.20(-0.88,0.47)$ \\
\hline CTA+/ASA- & $19(22.1)$ & $1.59(0.99-2.52)$ & $0.88(0.55-1.41)$ & \\
\hline CTA-IASA+ & $138(46.8)$ & $3.36(2.75-4.10)$ & $2.02(1.64-2.51)$ & \\
\hline CTA-IASA- & $319(13.9)$ & Reference & Reference & \\
\hline \multicolumn{5}{|l|}{ Age $18-29$ yrs } \\
\hline CTA+/ASA+ & $22(39.3)$ & $2.88(1.82-4.55)$ & $1.50(0.92-2.45)$ & $-0.38(-1.73,0.97)$ \\
\hline CTA+/ASA- & $8(33.3)$ & $2.44(1.19-5.01)$ & $1.23(0.59-2.55)$ & \\
\hline CTA-IASA+ & $21(42.9)$ & $3.14(1.97-5.01)$ & $1.66(1.03-2.69)$ & \\
\hline CTA-IASA- & $108(13.7)$ & Reference & Reference & \\
\hline \multicolumn{5}{|l|}{ Age $30-49$ yrs } \\
\hline CTA+/ASA+ & $18(29.5)$ & $2.37(1.44-3.91)$ & $1.49(0.89-2.49)$ & $-1.01(-2.44,0.42)$ \\
\hline CTA+/ASA- & $6(21.7)$ & $1.75(0.71-4.28)$ & $0.96(0.39-2.38)$ & \\
\hline CTA-IASA+ & $41(51.3)$ & $4.12(2.86-5.91)$ & $2.55(1.74-3.72)$ & \\
\hline CTA-IASA- & $102(12.5)$ & Reference & Reference & \\
\hline \multicolumn{5}{|l|}{ Age $50-69$ yrs } \\
\hline CTA+/ASA+ & $26(45.6)$ & $2.87(1.85-4.46)$ & $1.71(1.08-2.72)$ & $0.68(-0.30,1.66)$ \\
\hline CTA+/ASA- & $3(11.1)$ & $0.70(0.22-2.21)$ & $0.42(0.13-1.38)$ & \\
\hline CTA-IASA+ & $47(44.8)$ & $2.82(1.97-4.03)$ & $1.60(1.06-2.43)$ & \\
\hline CTA-IASA- & $83(15.9)$ & Reference & Reference & \\
\hline \multicolumn{5}{|l|}{ Age $\geq 70$ yrs } \\
\hline CTA+/ASA+ & $9(40.9)$ & $2.49(1.17-5.31)$ & $2.02(0.93-4.35)$ & $-0.46(-2.56,1.64)$ \\
\hline CTA+/ASA- & $3(25.0)$ & $1.52(0.46-5.02)$ & $1.08(0.31-3.70)$ & \\
\hline CTA-IASA+ & $29(47.5)$ & $2.89(1.70-4.91)$ & $2.40(1.40-4.20)$ & \\
\hline CTA-IASA- & $26(16.5)$ & Reference & Reference & \\
\hline
\end{tabular}

* Estimated from Cox regression assuming equal time at risk.

† Overall model adjusted for age; ISS; diagnosis of myocardial infarction, congestive heart failure, or peripheral vascular disease; PRBC units transfused within the first 24 hours of admission; and INR $\geq 1.2$ at admission.

$\ddagger$ Based on adjusted models.

assessed in the Cervical Artery Dissection in Stroke Study (CADISS). ${ }^{24}$ However, TCVI differs from spontaneous dissection in several ways: 1) most TCVI lesions are initially asymptomatic and discovered by screening imaging; 2) high-energy TCVI is likely to be biologically distinct from spontaneous dissections, which are frequently related to underlying connective tissue abnormalities; ${ }^{3,39} 3$ ) the majority of patients with blunt trauma experience a hypercoagulable state ${ }^{10,20,29}$ soon after injury ${ }^{34}$ that coincides with the time course of ischemic stroke with TCVI; and 4) patients with TCVI often have other traumatic injuries, making their management more complex than in patients with spontaneous dissection. Therefore, TCVI should be considered to be a distinct clinical setting for evaluating potential hemorrhagic risks of antiplatelet therapy.

The mechanism of most ischemic strokes due to TCVI is thromboembolic. ${ }^{16,28,36}$ Although a survey of clinicians found that their preferences are divided between anticoagulation and antiplatelet agents, ${ }^{19}$ and the most widely reported antithrombotic strategy is systemic anticoagulation, ${ }^{14}$ hemorrhagic complication rates of $8 \%-16 \%$ have been reported with anticoagulation in patients with blunt trauma, $8,11,26,27$ and approximately one-third of patients with TCVI are not candidates for systemic anticoagulation due to concomitant injuries. ${ }^{37,41}$ Antiplatelet agents are a popular alternative to anticoagulation in this setting. Two retrospective studies found lower rates of bleeding complications with antiplatelet agents when compared to anticoagulation. ${ }^{9,41}$ Furthermore, antiplatelet agents carry a theoretical advantage in that the mechanism of stroke in TCVI is usually artery-to-artery embolism, and antiplatelet agents may be more appropriate in the high-flow, platelet-rich arterial environment. Indeed, platelets are the dominant contributors to hypercoagulability after trauma ${ }^{17}$ and a significant percentage of patients with trauma develop thrombocytosis during the hospitalization, ${ }^{33,40}$ so antiplatelet therapy seems to be a logical choice for antithrombotic therapy.

Our findings are consistent with studies of the use of antiplatelet agents for the primary prevention of stroke in other clinical settings. For example, treatment with aspirin for the primary prevention of stroke in the general population is associated with an increased risk of hemorrhagic complications, such as gastrointestinal bleeding and hem- 
orrhagic stroke. ${ }^{2,6,32}$ In fact, the use of aspirin for primary stroke prevention in the general population does not appear to have a net benefit in terms of stroke risk reduction because of hemorrhagic complications. ${ }^{25}$ Primary stroke prevention with aspirin does appear to provide net benefit in specific subgroups, such as women with diabetes and elevated cardiovascular risk and some patients with chronic kidney disease. ${ }^{25}$

The full antiplatelet effect of aspirin occurs within 30 minutes of ingestion, persists for the platelet lifespan, ${ }^{23}$ and is dose dependent. Lower doses of aspirin (e.g., $81 \mathrm{mg}$ ) inhibit prostaglandin H-synthase 1 (COX-1), whereas higher doses (e.g., $325 \mathrm{mg}$ ) inhibit both COX-1 and prostaglandin H-synthase 2 (COX-2). ${ }^{30}$ Low-dose aspirin seems to be effective for the primary prevention of stroke in some populations, such as women with diabetes,${ }^{25}$ but is insufficient in other populations, such as patients with atrial fibrillation without anticoagulation. ${ }^{1}$ It has been the practice at our center to treat all patients with evidence of asymptomatic TCVI with $325 \mathrm{mg}$ aspirin daily; this dose is within the American Heart Association (AHA) guidelines for dosing of aspirin for secondary prevention of stroke (50-325 mg daily). ${ }^{21}$ However, an analysis of bleeding complications in 31 randomized trials comparing different doses of aspirin found a higher total risk of bleeding with high-dose $(>200$ $\mathrm{mg})$ compared to low-dose $(<100 \mathrm{mg})$ aspirin. ${ }^{35}$ Thus, it is possible that low-dose aspirin may carry a lower risk of transfusion in patients with TCVI, although it is not clear whether low-dose aspirin would also offer equivalent protection against thromboembolic stroke.

Our analysis was limited to transfusions $>24$ hours after admission. The majority of transfusions in trauma patients are given within 24 hours, ${ }^{4,12,42}$ and any effect of a daily regimen of aspirin, which is begun in most patients with CT angiographic evidence of TCVI within the first day of admission, is likely to be apparent after this initial period.

Differing risks of transfusion with different age groups are likely due to a complex combination of factors. Patterns of injury vary between age groups, even when controlling for ISS; whereas motor vehicle crashes are more common among younger patients (with a higher chance of multiple injuries), falls are more common among older patients (with a relatively lower chance of multiple injuries).,13 In addition, the clinical threshold for transfusion is also likely to differ between age groups; for instance, older patients with trauma are more likely to have preexisting cardiopulmonary disease and may be less able to tolerate blood loss.

\section{Limitations of the Study}

This study is based on a large single-center database of patients who present with trauma and on hospital radiology records. As with any large database, it is possible that some data were erroneous (e.g., some patients recorded as receiving aspirin may not have received it). In addition, comorbidity data were based on ICD codes found within billing data. A main limitation to the use of data in the billing system is the lack of information regarding whether the diagnosis was present on admission; thus, it is possible that some diagnoses occurred during the patient's stay. Moreover, the definition of some of the comorbidities included codes for the injuries the patient sustained (e.g., cerebrovascular disease includes codes for subarachnoid and intracerebral hemorrhage and infarctions due to occlusions); without knowledge of "present on admission" status, though, it is impossible to determine which codes represent the history of these conditions or a condition associated with the patient's injury-related hospital encounter. However, there is no reason to believe the misclassification to be related to the CTA/ASA study group, and thus any bias will be nondifferential and will result in attenuation of associations toward the null (i.e., resulting in a more conservative estimate).

Another limitation of note-treatment with aspirin may not have been uniform among all patients classified as receiving aspirin. In addition, $2 \%-5 \%$ of the patients in each of the 4 categories in Table 1 were not listed as having a blunt trauma mechanism even though these patients were classified as having blunt trauma on admission. Thus, it is possible that some of the patients in this study actually had penetrating trauma, which would be expected to carry a higher risk of bleeding complications; however, with a similar proportion across the exposure groups, we expect any bias to be nondifferential and to cause reported associations to be underestimates of the true association. Finally, it is possible that patients had been exposed to aspirin or other antiplatelet agents prior to the occurrence of the injury and subsequent hospital admission. Although we were not able to collect data on prehospital exposure to antiplatelet agents, by stratifying by age we were able to minimize any bias resulting from lack of prehospital data.

\section{Conclusions}

Treatment with aspirin for the prevention of stroke in patients with initially asymptomatic TCVI carries a significantly increased risk of PRBC transfusion; however, this increased risk is no more than expected from the summed excess risks due to TCVI alone and aspirin use alone. Future studies are needed to determine if this risk is offset by a reduced risk of ischemic stroke.

\section{Acknowledgments}

We thank Karen Self for compiling the list of CTA studies and Holly Waller for help with the trauma registry.

\section{References}

1. Ansara AJ, Nisly SA, Arif SA, Koehler JM, Nordmeyer ST: Aspirin dosing for the prevention and treatment of ischemic stroke: an indication-specific review of the literature. Ann Pharmacother 44:851-862, 2010

2. Baigent C, Blackwell L, Collins R, Emberson J, Godwin $\mathrm{J}$, Peto R, et al: Aspirin in the primary and secondary prevention of vascular disease: collaborative meta-analysis of individual participant data from randomised trials. Lancet 373:1849-1860, 2009

3. Brandt T, Orberk E, Weber R, Werner I, Busse O, Müller BT, et al: Pathogenesis of cervical artery dissections: association with connective tissue abnormalities. Neurology 57:24-30, 2001

4. Como JJ, Dutton RP, Scalea TM, Edelman BB, Hess JR: Blood transfusion rates in the care of acute trauma. Transfusion 44:809-813, 2004 
5. Crawford JD, Allan KM, Patel KU, Hart KD, Schreiber MA Azarbal AF, et al: The natural history of indeterminate blunt cerebrovascular injury. JAMA Surg 150:841-847, 2015

6. De Berardis G, Lucisano G, D'Ettorre A, Pellegrini F, Lepore $\mathrm{V}$, Tognoni $\mathrm{G}$, et al: Association of aspirin use with major bleeding in patients with and without diabetes. JAMA 307:2286-2294, 2012

7. Demetriades D, Murray J, Martin M, Velmahos G, Salim A, Alo K, et al: Pedestrians injured by automobiles: relationship of age to injury type and severity. J Am Coll Surg 199:382387,2004

8. Eachempati SR, Vaslef SN, Sebastian MW, Reed RL II: Blunt vascular injuries of the head and neck: is heparinization necessary? J Trauma 45:997-1004, 1998

9. Edwards NM, Fabian TC, Claridge JA, Timmons SD, Fischer PE, Croce MA: Antithrombotic therapy and endovascular stents are effective treatment for blunt carotid injuries: results from longterm followup. J Am Coll Surg 204:1007-1015, 2007

10. Engelman DT, Gabram SG, Allen L, Ens GE, Jacobs LM: Hypercoagulability following multiple trauma. World J Surg 20:5-10, 1996

11. Fabian TC, Patton JH Jr, Croce MA, Minard G, Kudsk KA, Pritchard FE: Blunt carotid injury. Importance of early diagnosis and anticoagulant therapy. Ann Surg 223:513-525, 1996

12. Farion KJ, McLellan BA, Boulanger BR, Szalai JP: Changes in red cell transfusion practice among adult trauma victims. J Trauma 44:583-587, 1998

13. Fatovich DM, Jacobs IG, Langford SA, Phillips M: The effect of age, severity, and mechanism of injury on risk of death from major trauma in Western Australia. J Trauma Acute Care Surg 74:647-651, 2013

14. Foreman PM, Harrigan MR: Blunt traumatic extracranial cerebrovascular injury and ischemic stroke. Cerebrovasc Dis Extra 7:72-83, 2017

15. Franz RW, Willette PA, Wood MJ, Wright ML, Hartman JF: A systematic review and meta-analysis of diagnostic screening criteria for blunt cerebrovascular injuries. J Am Coll Surg 214:313-327, 2012

16. Griessenauer CJ, Fleming JB, Richards BF, Cava LP, Curé $\mathrm{JK}$, Younan DS, et al: Timing and mechanism of ischemic stroke due to extracranial blunt traumatic cerebrovascular injury. J Neurosurg 118:397-404, 2013

17. Harr JN, Moore EE, Chin TL, Ghasabyan A, Gonzalez E, Wohlauer MV, et al: Platelets are dominant contributors to hypercoagulability after injury. J Trauma Acute Care Surg 74:756-765, 2013

18. Harrigan MR, Falola MI, Shannon CN, Westrick AC, Walters $\mathrm{BC}$ : Incidence and trends in the diagnosis of traumatic extracranial cerebrovascular injury in the nationwide inpatient sample database, 2003-2010. J Neurotrauma 31:1056-1062, 2014

19. Harrigan MR, Weinberg JA, Peaks YS, Taylor SM, Cava LP, Richman J, et al: Management of blunt extracranial traumatic cerebrovascular injury: a multidisciplinary survey of current practice. World J Emerg Surg 6:11, 2011

20. Kaufmann CR, Dwyer KM, Crews JD, Dols SJ, Trask AL: Usefulness of thrombelastography in assessment of trauma patient coagulation. J Trauma 42:716-722, 1997

21. Kernan WN, Ovbiagele B, Black HR, Bravata DM, Chimowitz MI, Ezekowitz MD, et al: Guidelines for the prevention of stroke in patients with stroke and transient ischemic attack: a guideline for healthcare professionals from the American Heart Association/American Stroke Association. Stroke 45:2160-2236, 2014 (Erratum in Stroke 46:e54, 2015)

22. Kowalski RG, Haarbauer-Krupa JK, Bell JM, Corrigan JD, Hammond FM, Torbey MT, et al: Acute ischemic stroke after moderate to severe traumatic brain injury: incidence and impact on outcome. Stroke 48:1802-1809, 2017

23. Lange RA, Hillis LD: Antiplatelet therapy for ischemic heart disease. N Engl J Med 350:277-280, 2004

24. Markus HS, Hayter E, Levi C, Feldman A, Venables G, Norris J: Antiplatelet treatment compared with anticoagulation treatment for cervical artery dissection (CADISS): a randomised trial. Lancet Neurol 14:361-367, 2015

25. Meschia JF, Bushnell C, Boden-Albala B, Braun LT, Bravata DM, Chaturvedi S, et al: Guidelines for the primary prevention of stroke: a statement for healthcare professionals from the American Heart Association/American Stroke Association. Stroke 45:3754-3832, 2014

26. Miller PR, Fabian TC, Bee TK, Timmons S, Chamsuddin A, Finkle R, et al: Blunt cerebrovascular injuries: diagnosis and treatment. J Trauma 51:279-286, 2001

27. Miller PR, Fabian TC, Croce MA, Cagiannos C, Williams JS, Vang M, et al: Prospective screening for blunt cerebrovascular injuries: analysis of diagnostic modalities and outcomes. Ann Surg 236:386-395, 2002

28. Morton RP, Hanak BW, Levitt MR, Fink KR, Peterson EC, Vilela MD, et al: Blunt traumatic occlusion of the internal carotid and vertebral arteries. J Neurosurg 120:1446-1450, 2014

29. Park MS, Martini WZ, Dubick MA, Salinas J, Butenas S, Kheirabadi BS, et al: Thromboelastography as a better indicator of hypercoagulable state after injury than prothrombin time or activated partial thromboplastin time. J Trauma 67:266-276, 2009

30. Patrono C, García Rodríguez LA, Landolfi R, Baigent C: Low-dose aspirin for the prevention of atherothrombosis. $\mathbf{N}$ Engl J Med 353:2373-2383, 2005

31. Quan H, Sundararajan V, Halfon P, Fong A, Burnand B, Luthi JC, et al: Coding algorithms for defining comorbidities in ICD-9-CM and ICD-10 administrative data. Med Care 43:1130-1139, 2005

32. Raju N, Sobieraj-Teague M, Hirsh J, O’Donnell M, Eikelboom J: Effect of aspirin on mortality in the primary prevention of cardiovascular disease. Am J Med 124:621629, 2011

33. Salim A, Hadjizacharia P, DuBose J, Kobayashi L, Inaba K, Chan LS, et al: What is the significance of thrombocytosis in patients with trauma? J Trauma 66:1349-1354, 2009

34. Schreiber MA, Differding J, Thorborg P, Mayberry JC, Mullins RJ: Hypercoagulability is most prevalent early after injury and in female patients. J Trauma 58:475-481, 2005

35. Serebruany VL, Steinhubl SR, Berger PB, Malinin AI, Baggish JS, Bhatt DL, et al: Analysis of risk of bleeding complications after different doses of aspirin in 192,036 patients enrolled in 31 randomized controlled trials. Am J Cardiol 95:1218-1222, 2005

36. Srinivasan J, Newell DW, Sturzenegger M, Mayberg MR, Winn HR: Transcranial Doppler in the evaluation of internal carotid artery dissection. Stroke 27:1226-1230, 1996

37. Stein DM, Boswell S, Sliker CW, Lui FY, Scalea TM: Blunt cerebrovascular injuries: does treatment always matter? J Trauma 66:132-144, 2009

38. Tso MK, Lee MM, Ball CG, Morrish WF, Mitha AP, Kirkpatrick AW, et al: Clinical utility of a screening protocol for blunt cerebrovascular injury using computed tomography angiography. J Neurosurg 126:1033-1041, 2017

39. Uhlig P, Bruckner P, Dittrich R, Ringelstein EB, Kuhlenbäumer G, Hansen U: Aberrations of dermal connective tissue in patients with cervical artery dissection (sCAD). J Neurol 255:340-346, 2008

40. Valade N, Decailliot F, Rébufat Y, Heurtematte Y, Duvaldestin P, Stéphan F: Thrombocytosis after trauma: incidence, aetiology, and clinical significance. Br J Anaesth 94:18-23, 2005 
41. Wahl WL, Brandt MM, Thompson BG, Taheri PA, Greenfield LJ: Antiplatelet therapy: an alternative to heparin for blunt carotid injury. J Trauma 52:896-901, 2002

42. Wudel JH, Morris JA Jr, Yates K, Wilson A, Bass SM: Massive transfusion: outcome in blunt trauma patients. J Trauma 31:1-7, 1991

\section{Disclosures}

The authors report no conflict of interest concerning the materials or methods used in this study or the findings specified in this paper.

\section{Author Contributions}

Conception and design: all authors. Acquisition of data: Grif- fin, Falatko, Strickland. Analysis and interpretation of data: all authors. Drafting the article: Griffin, Falatko, Aslibekyan. Critically revising the article: Harrigan, Aslibekyan. Reviewed submitted version of manuscript: Griffin, Falatko, Strickland. Approved the final version of the manuscript on behalf of all authors: Harrigan. Statistical analysis: Griffin, Aslibekyan. Administrative/ technical/material support: Harrigan, Falatko. Study supervision: Harrigan.

\section{Supplemental Information}

\section{Previous Presentations}

The abstract was submitted to the 2018 International Stroke Conference, Los Angeles, CA (January 2018).

\section{Correspondence}

Mark R. Harrigan: University of Alabama, Birmingham, AL. mharrigan@uabmc.edu. 